\title{
Experts, outsiders or strangers? The self-positioning of highly skilled contractors
}

\author{
Melanie Bryant $^{\star}$ and Tul McKeown ${ }^{\dagger}$
}

\begin{abstract}
Low and high-skilled contractors are often positioned in an analogous way within the literature drawing attention to the benefits of highly skilled contracting in contrast to the precarious nature of low-skilled contracting. Highly skilled contractors are largely identified within the free agent view; as self-directed professionals who add significant value to client organisations. However, very little research has focused specifically on how highly skilled contractors identify themselves through the process of positioning. We present the findings of a qualitative study of 34 highly skilled contractors. We found that participants positioned themselves in three specific ways: as expert, outsider and stranger and theorise about why highly skilled contractors construct simultaneous but diverse positions of themselves. In doing so, we argue that developing a more thorough understanding of how highly skilled contractors identify themselves provides valuable insights for those tasked with managing different groups of workers in the one workplace.
\end{abstract}

Keywords: highly skilled contractors, positioning, identity, qualitative research

Received 17 June 2015. Accepted 20 August 2015

\section{INTRODUCTION}

7 he emergence of highly skilled contracting as an accepted profession reflects structural shifts in societal norms around ways of working. In contemporary organisational environments, a dual approach to recruiting and staffing to satisfy organisational needs is not uncommon and is evident in hiring a contract workforce alongside regular staff. Regardless of the type of work they do, contractors' employment status sits outside of the 'institutionalized system of social relations that define regular employment' (Osnowitz, 2010: 6), raising implications for how contractors are identified and viewed by others. The identification of contractors is largely determined by skill level. For example, discussions of contracting in the literature often refer to two distinct groups of workers: low- and high-skilled contractors. Low-skilled contractors are often associated with precarious work, and are thought to lack autonomy over their work choices. They are also likely to experience stigmatisation and be identified as being of low social status (Lee \& Frenkel, 2004; Boyce, Ryan, \& Morgeson, 2007). In comparison, highly skilled contractors are largely identified as self-directed professionals who add value to client organisations (Kunda, Barley, \& Evans, 2002).

One argument for the distinction between the two groups of workers is that highly skilled contractors are more likely to be highly educated and trained than low-skilled contractors. Therefore, they rarely

* Associate Professor of Organisation Studies, Swinburne Business School, Swinburne University of Technology, Hawthorn, Australia

$\dagger$ Senior Lecturer in Management, Department of Management, Monash University, Clayton, Australia

Corresponding author: mjbryant@swin.edu.au 
'experience the vicissitudes of a secondary labor market' (Kunda, Barley, \& Evans, 2002: 258) as a consequence. Furthermore, highly skilled contractors bring specialised expertise to an organisation, while low-skilled contractors are more likely to reflect managerial decisions to use contingent labour as a way of increasing workforce flexibility (Lee \& Frenkel, 2004). We argue that a common theme across the contracting literature is that high- and low-skilled contractors are largely positioned by researchers in an analogous way in which one group is compared with the other. While researchers have certainly explored the experiences of both groups of contractors (see e.g., Smith, 1997; Kalleberg, Reskin, \& Hudson, 2000; Kunda, Barley, \& Evans, 2002; Lee \& Frenkel, 2004), very little research has focused specifically on how highly skilled contractors identify and position themselves, and how this compares with the positioning of different types of contractors in the literature. Our aim in this paper is to contribute to the contracting literature by exploring how highly skilled contractors identify themselves through the construction of specific positions within a discursive context.

To address our aim, we discuss the findings of a qualitative study in which 34 highly skilled information technology (IT) contractors participated in semi-structured interviews. We approached the interviews from a practical-hermeneutic approach (Habermas, 1972), focusing on how individuals 'craft identities through interaction, or how they weave "narratives of self" in concert with others' (Alvesson, Ashcraft, \& Thomas, 2008: 8). Although identity and positioning are interwoven, we focus primarily on the theory of positioning to frame our data, exploring the 'characteristics [that] are attributed to an individual or a group' (Baert, 2012: 310) within the discursive context of the interview. Consequently, we analysed the interviews using a socio-cultural narrative approach in which we emphasised 'the broader interpretive frameworks that [participants] use to make sense of everyday happenings' (Grbich, 2007: 130), such as interactions with others at work and how these influence the construction of specific positions. We found that participants position themselves in three specific ways. The first of these is the position of expert in which participants emphasised their professional status and the high value service they provided to clients. The second position we discuss is the outsider in which participants reported of experiencing marginalisation through specific behaviour and organisational processes used to segregate them from regular staff. Finally, we discuss the position of stranger in which participants identified as neither belonging to nor being alienated from the organisations they contracted to. We theorise about different reasons why participants construct these divergent positions and discuss the theoretical and practical implications.

\section{HOW CONTRACTORS ARE POSITIONED WITHIN THE LITERATURE}

Discussions about contract workers have largely taken place within a broader discourse of economic and workforce flexibility. As Garsten (1999: 601) argued, the "flexibility discourse" is ripe with positive images of versatile organisations employing likewise versatile employees, challenging the traditional institutions of stable, enduring organisations and workforces'. Workforce flexibility has led to changes to labour market structures in which hiring contract workers has become a norm rather than an exception, reflecting a dual approach to workforce management. This approach enables 'firms to adjust their staffing levels, to bring workers in when needed, and to discard them when they are no longer needed' (Smith, 2001: 7). The use of terms such as discard draws attention to the positioning of contracting within broader employment, regardless of it being a widely used employment strategy. For example, contractors are viewed as experiencing a lack of or compromised autonomy on the basis of the current state of the labour market leaving contractors 'vulnerable to hardening employer tactics' (Vallas \& Prener, 2012: 334). Debates about contractor autonomy have been constructed primarily within a body of literature that highlights a duality between low and high-skilled contractors (as a starting point, see Zeytinoglu, 1999; Mangan, 2000; Kalleberg, 2011; Lane, 2011) in which one group of workers is often compared with the other. Although our focus in this paper is on highly skilled contractors, we 
argue that exploring literature around both high- and low-skilled contractors provides insight into the different ways in which contractors are positioned. We also argue that contractors' experiences are more nuanced and ambiguous than how they are often presented in the literature and that exploring only highly skilled contractors provides an incomplete picture of the broader challenges of contracting faced by both groups.

Discussions around low-skilled contracting largely position it as precarious work in which workers lack autonomy or choice over the type of work they engage in (Smith, 1997; Lee \& Frenkel, 2004). Low-skilled contracting is largely associated with the institutional or employment relations views in which traditional employment is considered 'a prescription for stable employment [and] the foundation for America's unique system of social welfare' (Kunda, Barley, \& Evans, 2002) as many employees receive benefits directly from employers. Consequently, contracting, especially at the low-skilled end, is largely identified as socially disadvantageous, particularly for ethnic minorities, refugees, welfare-to-work recipients, and some groups of women (Kalleberg, Reskin, \& Hudson, 2000; Heinrich, 2005). Workers within such groups have a higher likelihood of experiencing additional disadvantage by becoming trapped in a cycle of precarious and short-term work with limited options available to improve their position (see e.g., Kalleberg, Reskin, \& Hudson, 2000; Kalleberg, 2011).

While the American system of work does not necessarily apply to workers in other national contexts, it highlights the low social status of workers engaged in low-skilled contracting and that workers are likely to engage in such work on the basis of it being the only work available at the time (Collinson, 2004; Barley \& Kunda, 2006; Thiel, 2007). Lower levels of skill and education often possessed by workers in this category also means that workers experience stigmatisation (Smith, 1997; Lee \& Frenkel, 2004; Boyce, Ryan, \& Morgeson, 2007). This is particularly likely if workers engage in work that others perceive as menial or as consisting of socially taboo or even dirty aspects (Ashforth \& Kreiner, 1999, 2014). Such work can lead to the labelling of contract workers on the basis of their work sitting outside the norms of what is deemed to be socially acceptable work or ways of working (Becker, 1963). Lee and Frenkel (2004) demonstrated this in their research in which low-skilled contractors were labelled and referred to as boys by regular employees. Within the Korean context in which this study took place, labelling of this nature is highly derogatory and as one of the participants stated, 'we are treated as less worthy than dogs' (Lee \& Frenkel, 2004: 514). However, without the social status or power within the workplace, precarious workers in similar situations lack the voice needed to change their circumstances and are more likely to 'accommodate or quit' (Lee \& Frenkel, 2004: 509).

In comparison, highly skilled contractors are largely identified within the free agent view of contracting (Kunda, Barley, \& Evans, 2002; Barley \& Kunda, 2006). That is, they are positioned as autonomous workers who have chosen contracting as 'a self-directed career' (Vallas \& Prener, 2012: 332). Within this group, workers are also more likely to reflect 'a kind of libertarian, anti-corporate rebellion' (Barley \& Kunda, 2006: 47) in which they engage in contracting to avoid the constraints of working in bureaucratic organisations (Shane, 2008). Consequently, highly skilled contractors are less likely to merely engage in contract work on the basis of it being the only work available. Rather, they are more likely to consider themselves as a business (Watson, 2008) engaging in activities such as 'finding clients, maintaining expertise and ensuring long-term security' (Barley \& Kunda, 2006: 52). These activities, combined with the skill set and education associated with highly skilled contractors, has positioned them within the literature as individuals who are held in high esteem by others, adding significant value to organisations (Kunda, Barley, \& Evans, 2002: 234). The prevalence of highly skilled contractors in the labour market has also led to the construction of a new occupational identity referred to as the itinerant professional (Barley \& Kunda, 2006). Of note, Bidwell (2009) found that highly skilled contractors are not viewed overly differently from regular employees while present in organisations. However, they are more likely to be employed on projects requiring high levels of 
interdependence across different organisational groups and less likely to work on tasks that engage directly with organisational politics.

A limitation of categorising contractors according to the institutional and free agent views is that 'the discourse ... [is] too rigid - too black and white - to be believable' (Barley \& Kunda, 2006: 47). We argue that these perspectives present opposing views of contractors, suggesting that there are distinct differences across both low- and high-skilled contracting. Consequently, the ambiguities and diversity that occur within each group of workers (Kunda, Barley, \& Evans, 2002) are not often discussed. To counter the dominant positioning of highly skilled contractors, scholars have drawn attention to some of the complexities involved in work of this nature. For example, highly skilled contractors may seek out contract work through necessity rather than choice if permanent employment is unavailable (Kalleberg, 2000; Kalleberg, 2011). Further, highly skilled contractors may struggle with developing the skills necessary for a successful career in contracting, or might lack skills required to remain employable and adaptable to changing labour markets (Smith, 1997; Lane, 2011). Some contractors also miss the 'deeper involvement with organizational life' (Peel \& Boxall, 2005: 1689), which can have significant consequences for fulfilling social needs. Highly skilled contractors are also required to 'network even when they hate it, fight depression, keep their marriages intact, and buoy their self-esteem' (Smith, 2012: 154); they can also experience estrangement and alienation from others (Kunda, Barley, \& Evans, 2002). The analogous positioning of low- and high-skilled contractors also fails to engage with issues such as liminality. That is, both low and high-skilled contractors can fall between the cracks (Gossett, 2006) in organisations, on the basis that they can be 'drawn into extended circles of loyalty [yet lack] ... the structural bond created by a regular employment position' (Garsten, 1999: 603).

Within client organisations, highly skilled contractors also face the challenges of balancing their professional identity and personal values with insider norms: 'Contractors must navigate between autonomy and constraint, assuming responsibility for conforming to organisational norms, even as they also negotiate some latitude for deviance' (Osnowitz, 2010: 96). Contractors are also required to negotiate organisational controls. For example, managers and regular staff within client organisations can engage in 'identity-work [as] ... a significant medium and outcome of organizational control' (Alvesson \& Willmott, 2002: 622) over contractors. That is, overt strategies and tools can be used to not only physically and symbolically differentiate contract workers from regular staff, but also as a way of communicating the 'rules of the game' (Augustsson, 2012: 50). In addition to this, contractors who are employed through agencies can face conflicting interests between the agency and the client, requiring negotiation of the needs of both, while also working within a 'dualistic system of control' (Gossett, 2006: 385). These points not only question the level of self-direction and free choice that highly skilled contractors have; they also draw attention to tensions that highly skilled contractors have to manage in terms of positioning themselves as professionals.

\section{THEORETICAL FRAMEWORK: POSITIONING THEORY}

Harré and Van Langenhove (1991:395) describe a position as being:

... A metaphorical concept through reference to which a person's 'moral' and personal attributes as a speaker are compendiously collected. One can position oneself or be positioned as e.g. powerful or powerless, confident or apologetic, dominant or submissive, definitive or tentative and so on.

The act of positioning involves a 'process by which certain characteristics are attributed to an individual or a group or some other entity' (Baert, 2012: 310) through the use of both overt and nuanced speech acts (Davies \& Harré, 1999; Baert, 2012). This occurs through an ongoing dialogical process in which we position/reposition according to our expectations and standards around performance (Harré \& Van Langenhove, 1991; Parrott, 2003; Hermans \& Hermans-Konopka, 2010). Sabat (2003) argues that 
we engage in both an interactive component of positioning in which we ascribe features to others, while simultaneously engaging in a reflexive component in which we position ourselves. Through this process, individuals can construct multiple and even fragmented positions for themselves. While the former reflects the multitudes of personal and social identities that we construct and have constructed for us (e.g., see Alvesson, Ashcraft, \& Thomas, 2008; Alvesson, 2010), the latter emphasises the relationship within the self. It is within this space that we engage in activities such as 'self-conflict, self-criticism, self-agreement, and self-consultancy' (Hermans \& Hermans-Konopka, 2010: 121). Individuals also engage in processes of collective identification in order to position themselves. For example, a highly skilled contractor is likely to position themselves within a professional or occupational identity that 'serves the role of a stable template against which [they] can articulate a personal identity' (Taylor, Bougie, \& Caouette, 2003: 197) and compare themselves with others. In engaging in such processes, individuals are not only able to construct identity, they can also construct disidentity by actively separating themselves from others (Hall, 1997; Garcia \& Hardy, 2007). This occurs through elevation of one's position through self character enhancement, or through character assassination of another (Ainsworth \& Hardy, 2007; Harré \& Moghaddam, 2014).

Individuals can also engage in malignant positioning in which negative stereotypical storylines are constructed on behalf of others who may not be empowered to negotiate their own positions, such as those who are ill, socially disadvantaged, or merely absent from the interaction (Sabat, 2003; Taylor, Bougie, \& Caouette, 2003). When positioning of others takes place in their absence, construction of one's own position is more likely to involve dramatisation (Harré \& Van Langenhove, 1991) or linguistic acts such as gossip, stereotyping, or labelling (Becker, 1973; Kraus, 2013; Martinescu, Janssen, \& Nijstad, 2014). Furthermore, position construction can have a dramatic or performative nature in which an individual specifically seeks to communicate particular aspects of their personal identity (Harré \& Van Langenhove, 1991). In doing so, individuals can 'draw on particular narratives and discourses and the related categories [within these] to position themselves' (LaPointe, 2010: 3) in comparison to others. For example, the positioning of a highly skilled contractor is likely to be achieved through the construction of others within the same context as being 'less desirable, powerful and acceptable' (Garcia \& Hardy, 2007: 366). Garcia and Hardy also argue that the presence and the role of the audience are paramount to the construction of positions. That is, the audience acts as a co-constructor by providing cues, asking questions, seeking clarification, and negotiating with the participant for the positioning to be deemed believable (Riessman, 2008). We argue that these points provide a useful theoretical lens for exploring how highly skilled contractors identify and position themselves, as well as a foundation for exploring why such positions are constructed.

\section{METHODOLOGY}

We developed the research from a constructivist approach to allow for investigation of 'the multiple realities constructed by people and the implications of those constructions for their lives and interactions with others' (Patton, 2002: 96). This enabled us to explore not only how participants construct meaning and identity within the context of their own experiences and background, it also provided us with the opportunity to act as co-constructors within the research setting through an ongoing dialogue with the participant (Atkinson \& Housely, 2003; Lincoln, Lyneham, \& Guba, 2011). Consequently, we did not seek to generalise the findings of this research into other contexts; nor did we seek to compare and contrast experiences according to participant characteristics or demographics. Rather, our aim was to explore how individual participants interpret their experiences at work and how they identify and position themselves accordingly. A total of 34 participants were recruited for the study by advertising with an independent contractors' association and a contracting management firm in Melbourne, Australia. 
Of the participants, eight were female and 26 were male. Participants were IT professionals and employed across a range of sectors including banking, engineering, government and telecommunications. Experience in contracting varied across participants with 1 year being the least amount of time a participant had worked as a contractor and 30 years being the most amount of time. Participants were interviewed for the study during 2010; post the Global Financial Crisis of 2007-2008. Our study is concerned with understanding how individuals' construct their personal experiences of being a highly skilled contractor. However, we acknowledge that gender, the industry in which one works as a contractor, and the economic climate are all worthy contexts in which further research on highly skilled contractors should be developed. That is, it is likely that the experiences of highly skilled contractors differ across gender and industry and influence the ways in which contractors position themselves. It is also likely that positioning oneself as a highly skilled contractor is influenced by economic growth as opposed to economic decline.

Each participant took part in a semi-structured, qualitative interview (Patton, 2015) of up to one hour in duration. Interview questions focused on broad topics such as how the participant became a contractor; how participants perceived themselves and the work they perform; advantages and disadvantages of contracting; managing workflow; experiences of contracting with different organisations; and experiences of personal and professional management while working as a contractor. With the permission of the participants, each interview was digitally recorded and transcribed for analysis. We were specifically interested in analysing the data in a way that enabled us to explore how participants constructed their identities and positioned themselves discursively within the interview setting. To achieve this we engaged in a socio-cultural narrative analysis. The socio-cultural approach to narrative analysis focuses on the broader interpretive frameworks that individuals use to make sense of everyday settings, such as work, and the interactions that take place within such settings (Grbich, 2007). This approach to narrative analysis focuses on 'the content and context of the story ... how people make sense of events ... [and] the emotions and feelings [that] are displayed' (Grbich, 2007: 130).

As appropriate to a socio-cultural approach, we followed the tradition of thematic narrative analysis (Boje, 2001a; Riessman, 2008). The first stage of this involved working within single interview transcripts to identify key points and events within the participant's experience This was achieved through open and axial coding to identify descriptors within (rather than across) each transcript and the relationships that occurred around particular codes (Miles \& Huberman, 1994; Saldana, 2009). We then analysed the individual transcripts to explore how the story unfolded by 'ordering relevant episodes into a chronological' (Riessman, 2008: 57) order. We acknowledge that engaging in this process risks reducing a 'multilayered, hermeneutically organized and abundantly meaningful' (Polkinghorne, 1988: 126) story into a more simplistic representation of an individual's experience. However, doing so enabled us to focus on a combination of temporality and performance (Goffman, 1959 ) in which we could explore how important situations were defined and communicated by the participants within the broader 'flow of surrounding events' (Heeren \& Mason, 1981: 25). The final stage in our analysis involved thematically analysing across the individual narratives (Boje, 2001b). This enabled us to engage with common features and patterns that occurred across participants' experiences, which formed the themes discussed in this paper. Analysing the data thematically was not aimed at generalising our findings or discounting any reports that conflicted with such themes. Rather, the aim of the thematic analysis was to highlight shared experiences as well as to provide an interpretive framework to present the experiences of the participants.

\section{FINDINGS}

From the analysis, three prominent themes emerged from the data in terms of how participants positioned themselves consisting of the expert, the outsider, and the stranger. We discuss each 
of these in this section of the paper before theorising about possible reasons why participants construct such positions.

\section{The expert}

The first position that emerged from the data was that of the highly skilled contractor as expert. In constructing this position, participants clearly differentiated themselves from regular staff within their narratives, drawing attention to their status, the high-value service they believed they provided to organisations and the level of autonomy they felt they had over their work and careers. The construction of the expert position was initially evident in explanations about what a highly skilled contractor did. For example, two participants described their roles as providing specialised 'business science to people' $(9)^{1}$ or new 'ideas and designs and whatever they need' (32) that regular employees could not provide client organisations. A third participant reported that he brought to a client 'expertise that I have built up and knowledge that I have built up in the industry ... [I] bring that back to the industry for someone who might like to buy that service' (26).

The position of expert was also articulated in the self-labelling that several contractors engaged in. That is, participants used terms such as consultant, specialist or professional rather than contractor to identify themselves. One participant argued that specific terms were needed to identify the work that highly skilled contractors engaged in. For example, 'I am a consultant rather than a contractor ... contractors dig holes' (25). In addition, 'I am an IT professional; an IT specialist ... so I am willing to take on risk and offer my services' (10). Similarly:

A consultant tends to be self-managing, will seek to maximize the value, adding more value, they will offer to do more management of themselves and possibly of the work around them, [they have a] more entrepreneurial outlook on life, spend more time networking and looking for opportunities (4).

The comments above indicate that in positioning themselves as consultants or professionals, participants do or bring more to the organisation than regular employees. Participants also identified themselves as having more autonomy and control over their professional choices compared with regular staff: 'When you are [regular staff] in the workforce, you really have no control, your priorities are changed daily' (26); '[as a contractor] you are in charge of your own destiny' (21). Moreover, 'there are many permutations of employment; contracting is the best because our mindset is very clear. We manage ourselves and our future, our opportunities' (30). Participants also highlighted that they were better able to deliver outcomes to clients than regular staff on the basis of contractors possessing more specialised or different skills and knowledge: '[clients] have got somebody who has got good knowledge $\ldots$ and they have got somebody who can deliver an outcome' (26). Further, 'to get things done [organisations] have to put on contractors who have the knowledge, the background, [and] who can do things faster and better for them' (2).

While participants arguably position themselves as having expertise or ability that regular staff do not, another participant suggests that regular staff have competing priorities that they are required to manage, which impacts on their ability to complete tasks: '[staff] have a lot of side issues going on ... [therefore] we have more targets and more focus' (24). This comment could be interpreted as highly skilled contractors performing a different rather than better job than regular employees. However, a following comment suggested otherwise: 'we know how to deal with people; we can talk; we can communicate; whereas a lot of other [regular staff] in the industry are not very communicative or are so focused [on technical skills] that they don't know how to explain themselves properly' (1). This participant also indicated that contractors have a much better ability than regular staff to 'handle a high

1 Individual participants are identified using numbers from 1 to 34 . 
pressure situation and be confident ... without freaking out, without looking like an idiot' (1); while a further participant suggested that highly skilled contractors were much better at using their time than regular staff:

I've been around for a long, long time now and I reckon it really comes down to the fact that contractors are just straight out more productive. We don't come in and spend $40 \mathrm{~min}$ looking at our personal emails or reading the paper, chatting to friends. We come in and get down to work. We don't spend 30 min at the water cooler or go for long coffees without telling anyone, or complain about work-life balance... [We] just get on with the job and do the best we can (29).

In summary, we argue that in positioning themselves as experts, participants play up their value and skill-sets in terms of what they can offer organisations in comparison to regular staff. This is perhaps not unusual given the perspective of highly skilled contractors offered in the free agent view. However, the position of expert is complicated by the simultaneous identification of participants as outsiders, which we discuss in the next section.

\section{The outsider}

A second position that emerged from the data was the outsider. We borrow the term outsider from Becker (1963) who uses it to identify individuals or groups viewed by broader society as not conforming with social norms, which, in the case of this paper, arguably relate to social norms around ways of working. In positioning themselves as outsiders, participants drew attention to examples of being segregated from regular staff through organisational processes, and deliberately excluded from specific organisational functions or events. For example, 'it is very obvious that there is a difference between a contractor and an employee. As a contractor you don't even get invited to some presentations because [invitations] are sent to employees only (12)'. Similar sentiments are manifested in the following comments:

The first year where I am currently contracting I didn't get invited [to the Christmas party] because the operations manager made a conscious decision that I wouldn't get invited, even though other [contractors] were (24).

I can't see the logic behind [not inviting us to social events] because you are being treated like a bit of an outcaste, like a leper, and for what it would cost them to do that, I think the rewards outweigh the costs (21).

The position of outsider is further apparent in participant reports of physical symbols and artifacts used to identity contractors. For example, identification tags were used to differentiate contractors from regular employees: 'You will be given a different [identification] card or it will be a different colour' (10); 'There was a blue [identification card] for full-timers and red one for contractors' (8) and; '[The contractors identification card] had the word "contractor" on it ... [regular staff] would normally have a plastic badge as opposed to a paper one' (19). One of the participants above also explained that contractors were even identified differently at the staff canteen: 'as a contractor ... at the staff canteen you pay more money' (10), while a further participant reported that contractors were differentiated from regular staff through online systems:

There is an internal website and an internal intranet and the internal intranet has a permanent employee site and a contractor site. As a contractor you are completely segregated from everything else. My [immediate] boss doesn't treat me any [differently] but the company as a whole have different standards (14).

Other participants suggest that this segregation has consequences for performing work. That is, 'having different systems is really odd, especially when you need information from the staff site to do your work' (23); and, 'not being able to access information on the web limits your ability to be on top of what's going on in the company' (31). Participants also reported that they were identified differently from regular staff through separate expectations around hours and standards of work. For example, 
'employees work seven hours and twenty-one minutes and we work eight [hours]. And they recognize that eight should be a minimum' (19); 'I have got more [performance] targets [than permanent staff] (24)'. Further:

[The organisations I work for] have got very high expectations of the productivity of their contractors. They... reluctantly let you into presentations and reluctantly keep you filled in, in the loop about what's going on. They really hope you will stay at your desk and you will be there twelve hours per day and you will work (12).

Such comments are perhaps not surprising given the often higher rate of pay and independent status that contractors attract (Smith, 1997). However, several participants indicated that, unlike regular staff, they did not receive formal recognition for their work through feedback or rank, making it difficult to progress in terms of a highly skilled contracting as a profession: 'I have gone into positions where I took on more leadership, but I was never given the rank because I was a contractor' (10). Further:

You do a better job ... [but] you have no career path because you [can't expect] to go through the ranks [as a contractor]...Y You have to give up on the notion of a career. I really want to get somewhere, I want to see how far I can go, but I would need to go permanent for that ... and I can't get recognized for what I do on the basis of being a contractor (18).

In constructing the position of outsider, participants draw attention to some of the tensions that highly skilled contractors face, regardless of whether or not they are viewed or view themselves as experts. Participants also constructed a third position; that of the stranger, which we argues differs from the position of outsider, adding further complexities to the experiences of highly skilled contractors.

\section{The stranger}

The stranger differs from the outsider in that participants construct this position in a way that diverges from examples of being excluded or segregated. Garsten (1999: 607) describes the stranger as a contractor who is 'socially under-determined ... [and viewed by regular staff] as types, not persons'. In other words, highly skilled contractors who construct this position identify themselves as neither belonging nor excluded, but rather as socially absent in the realm of the client organisation, which we argue, moves beyond experiences of feeling alienated. It is within such reports that participants draw attention to the transactional nature of contracting, or feeling 'totally expendable' (25). For example, 'I feel utterly insecure in my current position ... like someone could walk over and end it with no warning' (18); 'I am completely expendable, and I'm not really sure [if it is the nature] of contracting, or [if] it has to do with the working atmosphere in my [current] employer' (23).

Other participants argued that highly skilled contractors are often used as gap fillers to provide expertise when organisations do not have enough regular staff: 'We are just there to fill a gap' (24); 'we are just treated as bums on seats' (1); 'they just hire in what they need when they need it' (34). Other participants identified themselves as fee-for-service providers, or, as one participant explained, 'we are merely a business transaction' (17). That is, participants recognised that they were desirable to clients on the basis of their skills, but were also aware that they were viewed as short-term labour. For example, 'they pay me; I am a contractor; I do the work; who cares?' (4). Such comments position the client organisations as hiring highly skilled contractors to meet organisational needs, or to provide a sense of flexibility, rather than being concerned about what contractors can bring to the social fabric of an organisation. While this resonates with literature focusing on the use of secondary workforces as a form of flexibility, it contrasts with participants' positioning of themselves as experts and complicates the notion of value that participants perceive that they bring to the organisation.

It could be that highly skilled contractors are less concerned about being part of the social context of organisations in comparison to regular employees. However, reports of exclusion in the previous 
section suggest that for some contractors, social needs are of importance. This is further reinforced by participant comments in which they view the transactional nature of contracting as being devoid of meaningful interpersonal relationships at work. For example, one participant suggested that his current clients knew so little about him or his work that he doubted they actually understood the contribution that he added to the organisation: '[The current clients] don't know me [and] don't care about my wellbeing at all and they don't care about my output; if they care about me, they [only] care about me as a number' (26). The lack of interpersonal relationships, and even compassion, is further evident in the following participant's comment in which she reported of feeling as though she was inconveniencing staff in a meeting when she became ill:

I was at work and started to feel ill and I got worse and worse and worse...I was getting clammy and I turned to the man next to me and I said, 'I'm sorry, I am unwell, I will just have to leave for a minute'. When I stood up he just looked at me as if to say 'can't you just wait 'til we are finished to go to the toilet'... When I came back, white in the face, not one of them asked me how I was (15).

Comments such as that above draw attention to the some of the difficulties associated with being a highly skilled contractor. This is further reflected in participant comments highlighting the difficulties associated with building relationships with others: 'Making friends can be tough in this business ... that is a definite downside' (28); 'going from contract to contract and having to start all over with new people, new faces is a challenge' (6). Further:

There is a plethora of different feelings and emotional feelings that go with an employee that certainly I haven't felt personally as a contractor because most of my contracts are probably too short to get that emotional involvement ... so you don't build up that rapport (9).

In comparison, several participants argued that being a stranger in client organisations has advantages. One participant articulated this as, 'you can take a no strings attached kind of approach to your work (19)'. The lack of social and emotional attachment associated with being a stranger was also reported as being beneficial by two other participants. For example, 'one thing I like about [contracting] is there is no emotional investment either in the work or the people that you work with' (5). Further, 'you can go and get the job done and then go home and focus on other things without having to worry about what's going on in the workplace' (21). Another participant argued that being a stranger was a normal and even necessary part of being a contractor:

There are some people that will care about other people all of the time, that is just a part of their nature. But as an organisation, they certainly care a lot more about employees than they do contractors. But contractors care a lot less about that. They need to have that as part of their nature; not to really get insulted if they are not brought into a strategic discussion or if there is a big decision made and they are not involved in that decision ... you really can't survive in the long term as a contractor if you cared about what people think (12).

While the benefits of being a stranger are clearly highlighted in the comments above, comments discussed earlier in this section demonstrate the ambiguity that being a stranger can have for some participants. We argue that such ambiguities become more apparent when compared with positions such as the expert, and are likely to create tensions for highly skilled contractors. We now tease out some of these tensions and discuss possible reasons why such positions are constructed simultaneously by highly skilled contractors.

\section{DISCUSSION}

In constructing themselves as experts, it is clear that participants position themselves in a way that plays up the value of highly skilled contractors in terms of what they bring to organisations. On the one hand, this finding is not surprising, particularly when considered from the free agent view of contracting. 
We argue that participants' construction of themselves as experts provides further evidence of the shift in labour markets in terms of highly skilled contracting being recognised as a career choice and a profession of its own right. However, we argue that the position of expert contradicts findings such as those of Vallas and Prener (2012) in which changing labour markets are advantageous to organisations but detrimental to workers, particularly those employed on a contract basis. That is, participants demonstrate within their examples that highly skilled contracting reflects a form of organising (Barley $\&$ Kunda, 2006) in which power has shifted further towards them with regards to having the ability to dictate their terms to organisations, even if contracts are for a short period of time (cf Garsten, 1999). However, these arguments are complicated by the simultaneous construction of positions in which participants not only downplayed the roles of regular employees, but also revealed multiple or fragmented identities within themselves, drawing attention to ambiguities and tensions within their reports.

Downplaying the roles of regular employees resonates with the findings of scholars such as Harré and Moghaddam (2003) and Taylor, Bougie, and Caouette (2003), who argue that individuals position themselves through a process in which they use the actions and behaviour of others as a template for identity construction. Through this process, highly skilled contractors not only construct their identities, they can also justify decisions, such as those around career choices. This was not only evident in participants' examples of being experts; it was also evident in examples of being an outsider or stranger. For example, while participants drew attention to vulnerabilities and feelings of alienation within their positioning as outsiders and strangers, they did so in a way that clearly positioned regular staff as receiving the financial and social benefits of being in secure employment, such as inclusion in social activities, shorter hours of work and career progression, while not working as hard as contractors. We argue that positioning self and others in this way reflects a process of normalising (Thompson, Harred, \& Burk, 2003; Ashforth, Kreiner, Clark, \& Fugate, 2007) in which participants construct an identity that reinforces their professional status to themselves and others.

Normalising through the construction of the expert identity can enable participants to deflect or downplay the negative aspects of work that they may experience (Schneider, 2003). Normalising is a strategy often used by workers to demonstrate the common features they share with other workers or occupational groups, or as a way of demonstrating that they fit in (Baglien \& Knopf, 2004; McPherson, 2010). For example, normalising is often discussed in the context of dirty or deviant occupations such as morticians, exotic dancers, or garbage collectors in which workers seek to play up common characteristics of their work as a way of managing the stigma attached to them (Thompson, 1991; Thompson, Harred, \& Burk, 2003). We argue that normalising in this sense is more likely to be a strategy used by low-skilled contractors on the basis of their work being socially undervalued, which raises questions around the perceived value of highly skilled contractors. However, we argue that highly skilled contractors also engage in normalising strategies but do so in a slightly different way. In constructing themselves as experts, participants do not seek to draw attention to experiences they share with regular employees. Rather, the position of expert reflects cultural templates or scripts that determine norms around highly skilled contractors and their work (Alvesson, Ashcraft, \& Thomas, 2008). That is, highly skilled contractors normalise according to perceived norms around their profession that determine how they should behave and act and where they sit on a social hierarchy in comparison to regular employees. In positioning themselves in a manner that downplays regular employees, highly skilled contractors reinforce their identity as workers seeking freedom from conventional ways of working (Becker, 1963; Kunda, Barley, \& Evans, 2002). They also position regular workers who might judge them in a negative light as neither 'competent or legitimately entitled to do so' (Becker, 1963: 1-2).

While the position of expert may reflect cultural templates associated with highly skilled contracting, the construction of simultaneous positions of outsider and stranger can reflect the multitude of forces 
that undermine participants' possibilities of living up to such ideals (Alvesson, Ashcraft, \& Thomas, 2008). For example, lacking the skills necessary to be a successful career contractor, or even having a preference for permanent employment could prevent highly skilled contractors from living up to the position of expert, even if they identify with the label discursively. Constructing multiple positions simultaneously can provide insight into such tensions and reflect the intra-personal challenges that contractors face in the workplace. That is, the construction of multiple, or fragmented, positions draws attention to the self-conflict and self-criticism (Hermans \& Hermans-Konopka, 2010) that highly skilled contractors can experience. Identifying in such diverse ways also reflects Goffman's (1959) notion of region behaviour in which the position of expert exhibits front stage region behaviour. Identity within the front region is carefully crafted for the benefit of the audience and to ensure that the individual provides a favourable impression of themselves. For example, 'the performance of an individual within a front region may be seen as an effort to give the appearance that his [sic] activity ... maintains and embodies certain standards' (Goffman, 1959: 107) such as those reflected within cultural scripts around highly skilled contractors should behave and perform.

In comparison to the front region, the contrasting positions of stranger or outsider reflect back stage region behaviour. Within the back stage anything that could discredit or disrupt (Goffman, 1959) the identity of the expert, such as fears, self-doubt or secrets, are constructed out of view of the audience and within the privacy of one's personal space. That is, experiences such as being devalued and ignored, not being invited to social functions, or not having access to the same resources as regular staff, could challenge or question the authenticity of the highly skilled contractor's performance as expert and even their value or worth in client organisations. We also argue that such experiences reveal commonalities with low-skilled contractors particularly around acceptance of contractors in workplaces, or perceptions of their value and worth. While highly skilled contractors may perceive themselves as being of high value, by being present in an organisation they 'embody social changes under way and challenge existing categories in the realm of work' (Garsten, 1999: 615). In other words, their presence can upset the social and normative order of organisations, or even raise fears amongst regular staff regarding their own employment security and longevity. Consequently, reports of being treated as outsiders or strangers may even reflect an organisation's attempts to control highly skilled contractors and how they identify with their work. For example, Augustsson (2012) argues that while contractors are appreciated in organisations, a clear hierarchical difference between them and regular employees exists. As such, contractors are 'treated differently than the regular staff (Augustsson, 2012: 59), which participants reflect through the construction of the outsider or stranger identity.

\section{CONCLUSION}

The construction of multiple positions within the narrative context involves a performative component and identifying in different ways could reflect interpretations of the situation [that highly skilled contractors] find themselves in and then adjusting their behavior' (Becker, 1963: 172) accordingly. Consequently, positioning can involve careful crafting of identities and, more specifically, tell us a lot about how highly skilled contractors position others. A common theme across the narratives is that regardless of how others view the participants, they are able to rise above adversity and the challenges of being treated as outsiders and still add value to the organisations they work for, reiterating the position of expert. Although this suggests that the expert position was dominant within the different themes, we argue that focusing only on this position provides a partial understanding of the experiences of highly skilled contractors. On the one hand the expert position or free agent view reflects the benefits of highly skilled contracting and further research about such benefits is necessary. However, identifying as an outsider or a stranger draws attention to ambiguities and tensions that are not often discussed in association with highly skilled contractors. In particular, we argue that our findings in this paper raise 
questions around the impact that highly skilled contractors can have when they are present in workplaces - whether this impact is known to them or not - and how this impact can lead to alienation of self and others. In positioning as experts, highly skilled contractors risk alienating regular workers, particularly if positioning takes place through day-to-day interactions and conversations with regular staff. For example, positioning regular workers as not being as skilled, able or talented as contractors can reflect inaccurate stereotypes. It can also reflect malignant or dramatised positioning of staff that participants engage in an attempt to differentiate themselves (Sabat, 2003; Harré \& Moghaddam, 2014).

Alternatively, identifying as an outsider or stranger reinforces Augustsson's (2012) view that contractors are deemed to be different, highlighting the impact that the workplace can have on highly skilled contractors. That is, if highly skilled contractors are viewed by regular staff as outsiders, they are likely to be socially excluded and experience stigmatisation or be viewed as not belonging, particularly if their presence is deemed to challenge social and organisational norms. Consequently, high- and low-skilled contractors may share similar experiences in terms of an inferior social status in some organisations, regardless of skill or education level (Lee \& Frenkel, 2004; Boyce, Ryan, \& Morgeson, 2007). This could lead to further division between different groups of workers, particularly if contractors engage in self-aggrandised behaviour (Dyer \& Keller-Cohen, 2000), or regular workers are unable to see the value that highly skilled contractors add to the organisation.

In terms of the benefits of this research for managers and organisations, we argue that understanding how highly skilled contractors view and position themselves provides insight into developing different or more effective ways of managing contract workers. While contractors and regular workers are different, we argue that if managers use vastly different strategies to manage contractors, a side effect may be that contractors become increasingly liminal in terms of 'transcending institutional boundaries' (Garsten, 1999: 615). This may have advantages for the contractor if they do not seek to develop social or emotional attachments with organisations. However, increased liminality could create situations in which other highly skilled contractors experience rising levels of alienation or detachment from the organisation and its goals. This should be of concern to managers on the basis that detachment from the organisation has the potential to cause increased levels of contractor turnover, or lower levels of work quality and productivity. From an organisational perspective liminality can also lead to higher levels of ambiguity for managers who manage contract workers, particularly in terms of maintaining organisational control. In concluding, we argue that further research regarding the effective management of highly skilled contractors is timely. We also call for developing a more thorough understanding of how staff in client organisations perceive highly skilled contractors and what their experiences of working with contractors are, for both topics will provide valuable insight into managing different groups of workers in the one workplace that is not yet readily available.

\section{ACKNOWLEDGEMENTS}

This manuscript is an original work that has not been submitted to nor published anywhere else.

All authors have read and approved the paper and have met the criteria for authorship.

The key contribution of this paper is to contribute to the literature on highly skilled contracting by exploring the various ways in which highly skilled contractors' identity and position themselves. This fits with the scope and aims of JMO by exploring how different organisational contexts impact on the experiences of contractors, and how, in turn, contractors impact on the organisational context. The paper draws from management and sociological theory and seeks to provide both theoretical and practical understandings of the experiences of highly skilled contractors that are not readily available within the current management and work literature. 


\section{References}

Ainsworth, S., \& Hardy, C. (2007). The construction of the older worker: Privilege, paradox and policy. Discourse and Communication, 1(3), 295-313.

Alvesson, M. (2010). Self-doubters, strugglers, storytellers, surfers and others: Images of self-identities in organization studies. Human Relations, 63(2), 193-217.

Alvesson, M., Ashcraft, K., \& Thomas, R. (2008). Identity matters: Reflections on the construction of identity scholarship in organization studies. Organization, 15(1), 5-28.

Alvesson, M., \& Willmott, H. (2002). Identity regulation as organizational control: Producing the appropriate individual. Journal of Management Studies, 39(5), 619-644.

Ashforth, B. E., \& Kreiner, G. E. (1999). "How can you do it?": Dirty work and the challenge of constructing a positive identity. Academy of Management Review, 24(3), 413-434.

Ashforth, B. E., \& Kreiner, G. E. (2014). Dirty work and dirtier work: Differences in countering physical, social, and moral stigma. Management and Organization Review, 10(1), 81-108.

Ashforth, B. E., Kreiner, G. E., Clark, M. A., \& Fugate, M. (2007). Normalizing dirty work: Managerial tactics for countering occupational taint. Academy of Management Journal, 50(1), 149-174.

Atkinson, P., \& Housely, W. (2003). Interactionism: An essay in sociological amnesia. London: Sage.

Augustsson, G. (2012). The organizational control of temporary workers: An interview study in Sweden. International Journal of Management, 29(3), 448-463.

Baert, P. (2012). Positioning theory and intellectual interventions. Journal for the Theory of Social Behavior, 42(3), 304-324.

Baglien, S., \& Knopf, J. (2004). Normalizing difference in inclusive teaching. Journal of Learning Disabilities, 37(6), 525-529.

Barley, S., \& Kunda, G. (2006). Contracting: The new form of professional practice. Academy of Management Perspectives, 20, 45-66.

Becker, H. (1963). Outsiders: Studies in the sociology of deviance. New York, NY: Free Press.

Becker, H. (1973). Outsiders: Studies in the sociology of deviance. New York, NY: The Free Press.

Bidwell, M. (2009). Do peripheral workers do peripheral work? Comparing the use of highly skilled contractors and regular employees. Industrial and Labor Relations Review, 62(2), 200-225.

Boje, D. (2001a). Narrative methods for organizational \& communication research. London: Sage.

Boje, D. (2001b). Narrative methods for organizational and communication research. London: Sage.

Boyce, A., Ryan, A., \& Morgeson, F. (2007). "Temporary worker, permanent loser?" A model of the stigmatization of temporary workers. Journal of Management, 33(5), 5-29.

Collinson, J. (2004). Occupational identity on the edge: Social science contract researchers in higher education. Sociology, 38, 313-329.

Davies, B., \& Harré, R. (1999). Positioning and personhood. In R. Harré, \& L. Van Langenhove (Eds.), Positioning theory: Moral contexts of international action (pp. 32-52). Oxford: Wiley-Blackwell.

Dyer, J., \& Keller-Cohen, D. (2000). The discursive construction of professional self through narratives of personal experience. Discourse Studies, 2(3), 283-304.

Garcia, P., \& Hardy, C. (2007). Positioning, similarity and difference: Narratives of individual and organizational identities in an Australian university. Scandinavian Journal of Management, 23, 363-383.

Garsten, C. (1999). Betwixt and between: Temporary employees as liminal subjects in flexible organizations. Organization Studies, 20(4), 601-617.

Goffman, E. (1959). The presentation of self in everyday life. New York, NY: Anchor Books.

Gossett, L. (2006). Falling between the cracks: Control and communication challenges of a temporary workforce. Management Communication Quarterly, 19(3), 376-415.

Grbich, C. (2007). Qualitative data analysis: An introduction. London: Sage.

Habermas, J. (1972). Knowledge and human interests. London: Heinemann.

Hall, S. (1997). The spectacle of the other. In S. Hall (Ed.), Representation: Cultural representations and signifying practices (pp. 233-279). London: Sage.

Harré, R., \& Moghaddam, F. (2003). Introduction: The self and others in traditional psychology and in positioning theory. In R. Harré, \& F. Moghaddam (Eds.), The self and others: Positioning individuals and groups in personal, political and cultural contexts (pp. 1-11). Westport, CT: Greenwood Publishing Group. 
Harré, R., \& Moghaddam, F. (2014). Positioning theory. In N. Bozatzis, \& T. Dragonas (Eds.), The discursive turn in social psychology (pp. 129-138). Ohio: Taos Institute.

Harré, R., \& Van Langenhove, L. (1991). Varieties of positioning. Journal for the Theory of Social Behavior, 21(4), 393-407.

Heeren, J., \& Mason, M. (1981). Talk about visions: Spiritual readings as deviant work. Deviant Behavior, 2(2), 167-186.

Heinrich, C. (2005). Temporary employment experiences of women on welfare. Journal of Labor Research, 26, 335-350.

Hermans, H., \& Hermans-Konopka, A. (2010). Dialogical self-theory: Positioning and counter-positioning in a globalizing society. Cambridge: Cambridge University Press.

Kalleberg, A. (2011). Good jobs, bad jobs: The rise of polarized and precarious employment systems in the United States. New York, NY: Russell Sage Foundation.

Kalleberg, A., Reskin, B., \& Hudson, K. (2000). Bad jobs in America: Standard and nonstandard employment relations and job quality in the United States. American Sociological Review, 65, 256-279.

Kalleberg, A. L. (2000). Nonstandard employment relations: Part-time, temporary and contract work. Annual Review of Sociology, 26(1), 341.

Kraus, W. (2013). A quest for a third space: Heterotopic self-positioning and narrative identity. In C. Holler and M. Klepper (Eds.). Rethinking narrative identity: Persona and perspective (69-84). Amsterdam: John Benjamin Publishing Co.

Kunda, G., Barley, S., \& Evans, J. (2002). Why do contractors contract? The experience of highly skilled technical professionals in a contingent labor market. Industrial and Labor Relations Review, 55(2), 234-261.

Lane, C. (2011). A company of one: Insecurity, independence, and the new world of white-collar unemployment. New York, NY: ILR Press.

LaPointe, K. (2010). Narrating career, positioning identity: Career identity as a narrative practice. Journal of Vocational Behavior, 77, 1-9.

Lee, B., \& Frenkel, S. (2004). Divided workers: Social relations between contract and regular workers on a Korean auto company. Work, Employment and Society, 18, 507-530.

Lincoln, Y., Lyneham, S., \& Guba, E. (2011). Paradigmatic controversies, contradictions and emerging confluences; revisited. In N. Denzin, \& Y. Lincoln (Eds.), The sage handbook of qualitative research (pp. 97-128). London: Sage.

Mangan, J. (2000). Workers without traditional employment: An international study of non-standard work. Gloucester: Edward Elgar.

Martinescu, E., Janssen, O., \& Nijstad, B. A. (2014). Tell me the gossip the self-evaluative function of receiving gossip about others. Personality and Social Psychology Bulletin, 40(12), 1668-1680.

McPherson, M. (2010). 'I integrate therefore I am': Contesting the normalizing discourse of integration through conversations with refugee women. Journal of Refugee Studies, 23(4), 546-570.

Miles, M., \& Huberman, A. (1994). Qualitative data analysis: An expanded sourcebook (2nd ed.). Thousand Oaks, CA: Sage.

Osnowitz, D. (2010). Freelancing expertise: Contract professionals in the new economy. Cornell: Cornell University Press.

Parrott, W. (2003). Positioning and the emotions. In R. Harré, \& F. Moghaddam (Eds.), The self and others: Positioning individuals and groups in personal, political, and cultural contexts (pp. 29-43). Wetsport, CT: Praeger.

Patton, M. (2002). Qualitative research and evaluation methods (3rd ed.). Thousand Oaks, CA: Sage.

Patton, M. (2015). Qualitative research \& evaluation methods (4th ed.). Thousand Oaks, CA: Sage.

Peel, S., \& Boxall, P. (2005). When is contracting preferable to employment? An exploration of management and worker perspectives. Journal of Management Studies, 42(8), 1675-1697.

Polkinghorne, D. (1988). Narrative knowing and the human sciences. Albany, NY: State University of New York.

Riessman, C. (2008). Narrative methods for the human sciences. Los Angeles: Sage.

Sabat, S. (2003). Malignant positioning and the predicament of people with Alzheimer's disease. In R. Harré, \& F. Moghaddam (Eds.), The self and others: Positioning individuals and groups in personal, political and cultural contexts (pp. 85-98). Westport, CT: Praeger.

Saldana, J. (2009). The coding manual for qualitative researchers. Los Angeles: Sage.

Schneider, B. (2003). Narratives of schizophrenia: Constructing a positive identity. Canadian Journal of Communication, 28, 185-201.

Shane, S. A. (2008). The illusions of entrepreneurship: The costly myths that entrepreneurs, investors, and policy makers live by. New Haven, CT: Yale University Press.

Smith, V. (1997). New forms of work organization. Annual Review of Sociology, 23, 315-339. 
Experts, outsiders or strangers?

Smith, V. (2001). Teamwork vs. tempwork. In D. Cornfield, K. Campbell, \& H. McCammon (Eds.), Working in restructured workplaces: Challenges and new directions in the sociology of work (pp. 7-28). Thousand Oaks, CA: Sage.

Smith, V. (2012). "You get the economy you choose": The political and social construction of the new economy. Work \& Occupations, 39(2), 148-156.

Taylor, D., Bougie, E., \& Caouette, J. (2003). Applying positioning principles to a theory of collective identity. In R. Harré, \& F. Moghaddam (Eds.), The self and others: Positioning individuals and groups in personal, political and cultural contexts (pp. 197-215). Westport, CT: Praeger.

Thiel, D. (2007). Class in construction: London building workers, dirty work and physical cultures. British Journal of Sociology, 58(2), 227-251.

Thompson, W., Harred, J., \& Burk, B. (2003). Managing the stigma of topless dancing: A decade on. Deviant Behavior, 24(6), 551-570.

Thompson, W. E. (1991). Handling the stigma of handling the dead: Morticians and funeral directors. Deviant Behavior, 12(4), 403-429.

Vallas, S., \& Prener, C. (2012). Dualism, job polarization, and the social constrution of precarious work. Work and Occupations, 39(4), 331-353.

Watson, T. (2008). Managing identity: Identity work, personal predicaments and structural circumstances. Organization, 15, 121-143.

Zeytinoglu, J. (1999). Changing work relationships in industrialized economies. Amsterdam, PA: John Benjamins. 